\title{
Motivations and Challenges in MOOCs with Eastern Insights
}

\author{
Sheng-Hua Zhong, Qun-Bo Zhang, Zheng-Ping Li, and Yan Liu
}

\begin{abstract}
Massive open online courses (MOOCs) are the latest e-learning initiative to attain widespread popularity in the world. Unfortunately, nearly all of these studies are built from western insights. Thus, there is a need for a thematic and practical analysis of related studies to bring a better understanding of MOOCs with eastern insights. In this paper, a study is conducted focusing on the use of MOOCs from the eastern perspective. Our primary goal is to summarize the motivations and challenges of using MOOCs, as well as to identify issues that haven't yet to be fully addressed or resolved. In this paper, we employed different methodologies that included the use of a questionnaire survey and activity data analysis. The results of this study may enhance our understanding of challenges of teaching and learning in MOOCs and help educators develop MOOCs with eastern insights.
\end{abstract}

Index Terms - Eastern insights, human engagement, massive open online courses (MOOCs), motivations and challenges of MOOCs.

\section{INTRODUCTION}

Throughout history, educators have always been intrigued with the potential of technology to help transform education and improve student learning [1]. It is well known if teachers and researchers are able to analyze their own teaching techniques and understand the differences and needs of students, the educational process is likely to optimize for both teachers and their students [2]. Thus, educators expect the progress of teaching techniques could provide a method to know more about how students perceive and distribute information. Recently, a lot of education scientists have been talking about "changing education paradigm" [3]. As we known, the new education paradigms, Massive Open Online Courses (MOOCs) have brought about a revolution in education. In fact, The New York Times went so far as to declare 2012 as "The Year of the MOOC" [4].

The term "MOOCs" was originally proposed by George Siemens and Stephen Downs in 2008. It was used to describe a course offered in Canada in which the enrolment was opened online to any person. This means that, whatever your age, gender, occupation, and educational background, you could take part in this course. It made more than 2000 people signed up for this course. Since then, this term has gained popularity in the western countries especially when Sebastian

Manuscript received March 30, 2015; revised August 11, 2015

S.-H. Zhong, Q. B. Zhang, and Z. P. Li are with the Shen Zhen University, 518000, Shen Zhen, Guang Dong, China (e-mail: csshzhong@szu.edu.cn, 2011150145@szu.edu.cn,2011150020@szu.edu.cn).

Y. Liu is with the Hong Kong Polytechnic University, Hong Kong, China (Corresponding author. e-mail: csyliu@ comp.polyu.edu.hk).
Thrun, a Stanford professor, offered a course of artificial intelligence for free [5]. And his course attracted close to a quarter million people signed up.

MOOCs have important differences from previous approaches to online education. Most importantly, MOOCs are free and open to all, which attract larger audiences than traditional online education [6]. Basically, any individual with an Internet connection can join a MOOC, to access the available resources, interact with other students, share and discuss what they have learned with others on Discussion forums [7]. From the content comparisons among various educational formats [8], MOOCs are characterized by its natural openness. Based on its openness, advocates of the MOOCs believe that MOOCs can offer educational benefits to higher education institutes, professors and students [9]. Some of the proponents believe that MOOCs represent the ultimate democratization of education, by making education more accessible to as many people as possible [10]. Others think that MOOCs can help to increase the prestige of an institution, or as a tool for universities to market themselves to potential students, faculty, and donors [11], [12] as well as allowing teachers or researchers to experiment with the pedagogy of teaching online courses to large number of students [9]. Despite the momentum for MOOCs, on the other hand, skeptics of MOOCs are also widespread. The most common criticism is the completion rates of these classes are dismal compared to traditional education even the traditional online education. It is often mentioned that $90 \%$ of people who signed up for these courses don't complete the courses. Although completion rate may not be the best measure to evaluate learning results in MOOCs [13], but the low rates do raise questions regarding their effectiveness [14]. Another concern is quality. The loose structure of MOOCs makes quality or even measuring obtainable learning goals difficult [15].

\section{PURPOSE OF STUDY}

Currently, MOOCs attain widespread popularity among many universities in western countries. For example, as one of the fastest growing MOOC providers, Coursera has more than 30 university partners including Princeton, Brown, Columbia, Duke, Stanford, and Johns Hopkins [9]. It has registered 2.8 million students and sees 1.4 million course enrollments every month in 2013 [16]. Currently, Coursera has more than 100 university partners. It has already attracted 22 million participants from 190 different countries. In their forum, worldwide students have already posted more than 590 thousand topics. As another famous MOOC provider, edX provided more than 300 courses in many areas of study, 
including humanities, math, computer science, and physics. edX has 38 chapter members which are the leading global universities of edX consortium such as: MIT, Harvard University, University of Toronto, University of Tokyo, The Hong Kong University of Science and Technology, Peking University, and Tsinghua University. It also invited some global schools, non-profits, corporations, and international organizations as edX members, including: BITSx, GEMS Education, Microsoft, and IEEEx. Many existing studies are based on the qualitative analysis of data on these platforms [7]-[9], [15].

Unfortunately, nearly all of these studies are built by integrating western insight into human engagement studies. In this context, there is a need for a thematic and practical analysis of related studies to bring a better understanding of MOOCs under eastern culture. Specifically, the focus of our study is on the motivations and challenges related to the use of MOOCs. These include student motives for signing up MOOCs, student attitudes toward MOOCs, student challenges of learning in a MOOC, as well as instructors' methods used to engage students. This article also tries to identify the important issues that yet to be fully addressed which can suggest directions for further work.

\section{EXPERIMENTAL METHODS}

In this paper, our study is based on one MOOC course, Foundation of Computer Science (FOC), offered by Shen Zhen University in partnership with the online learning platform called "Chaoxing". This course is structured similar to a traditional course with all content predefined by the instructor ("XMOOC") [17]. Different with cMOOCs that are based on connectivism, xMOOCs are based on the theoretical presentation of the learning context, supplemented by interactive tasks and discussion boards activities. xMOOCs' learning objectives are predefined by the courses' instructors, while the participants' communication is limited [18].

To this course, each week, a set of videos (6-to-21), called lecture sequence was released. Most of them $(66 \%)$ were 3-to-10 minutes in length. Interspersed among these videos are online exercises that give students an opportunity to put into practice the concepts covered in the videos. A few lecture videos incorporated open-ended questions. All of the videos used visualizations, such as: animations, stimulations, figures, graphs, schemes, 3D pictures, tables, and examples from the daily life. The course also includes a discussion forum where students can have questions answered by other students, the corresponding lecturers, or other teaching assistants. In every chapter, the lecturer added summary points at the end of each lecture. The assignments of this course were divided into two types: 1) Assignments, which included: integrated exercises in the lecturer videos, chapter-based quizzes, and final exams, 2) Discussion forums activities, which were graded according to the average of votes, posts, and views.

In this study, as existing work [19], different methodologies were used in the collection, analysis, and interpretation of data. The research included two tools:

\section{A. Questionnaire}

A questionnaire survey was conducted that examined students' views about learning via MOOCs and their preferred ways for constructing knowledge. Students were asked to provide details about MOOCs they took, such as: educational backgrounds and objectives, methods of learning, learning styles, learning status and progress, attitudes toward MOOCs. They were also asked to evaluate the advantages and disadvantages of MOOCs and provide ideas for its improvement. The study included 186 undergraduate students from Shen Zhen University, $76 \%$ of those who reported their gender were male. The average age of all students is 19.8 years. These students major in a variety of disciplines, including: computer science, architecture, civil engineering, and optoelectronics engineering and so on.

\section{B. Daily Activity Data}

We also recorded, collected and analyzed the daily activity data for all people signed up for this course. In total 1783 participants, 1190 people are from Shen Zhen University, 554 people are from other universities in Mainland China, and 39 people are from other web users. The activity data contain number of visits, number of votes, number of posts, grades for assignments and quizzes, number of reviews for each video lecture, and grade for final online exam.

\section{RESUlTS}

\section{A. Motivations of Learning in MOOCs}

From the questionnaire survey, we know most of students $(85 \%)$ in this course often surfs the Internet, but only $6 \%$ of them have interests of programming or other computer science related skills before. Different from the popularity of MOOCs in western countries, only $4 \%$ students had real experiences of MOOC on the international platforms (Coursera, edX, Udacity, and so on), and another $4 \%$ had experience on some Chinese platforms. $65 \%$ students have heard the term or the concept of "Online Courses" before, while $27 \%$ knew nothing about it. There are no differences between majors or genders.

From the questionnaire survey, most of the participants (55\%) chose their MOOC because it seemed interesting and a good way to acquire new knowledge. $27 \%$ chose their MOOC because it allowed them to acquire new skills and helpful to job hunting. To the advantages of MOOCs, $85 \%$ indicated that the convenience of working through a MOOC at their own time and location. $61 \%$ mentioned the repeatability of MOOCs is helpful for them to understand the content deeply. $28 \%$ referred to the contribution of Discussion forum. $19 \%$ admitted the effectiveness of various visualized lectures materials. Overall, about $27 \%$ indicated that they got used to learning by MOOC, and they will prefer to learn through a MOOC rather than the traditional classroom teaching. 55\% reported that they would select MOOC or traditional education based on the nature of the course. Only $12 \%$ thought, compared with MOOC, the traditional classroom teaching is better for them. Although the number of recommendation for MOOCs is lower than the existing work [9], considering the fact that most of students get used to traditional education and did not have any experience of MOOCs, we could say they had a good experience in learning 
a MOOC.

As we known, MOOCs are helpful to increase an institution's reach and even the prestige because they could attract a large number of students in worldwide. From the study of the data generated by MIT's first MOOC, "Circuits and Electronics" $(6.002 \mathrm{x})$ by a team of multidisciplinary researchers from MIT and Harvard [20], we know their registered students came from 194 countries, virtually all in the world. The top five countries were the United States $(26,333)$, India (13,044), the United Kindom (8,430), Colombia $(5,900)$, and Spain $(3,684)$. Although Shen Zhen University is far less famous than the universities in Ivy League University, and the video lectures of FOC are all in Chinese language, it still attracted about 600 people from outside Shen Zhen University. In Fig. 1, we provided the pie chart of registrants in FOC. From this figure, we can find most of these students come from the universities in Mainland China, which do not provide the similar courses due their background, such as Southern Medical University. The farthest student located in Chang Chun, the northernmost part of China. The distance between Chuang Chun to Shen Zhen is about 1,926 miles, which is further than Paris to Moscow. It is obviously that MOOCs provide the convenience for these students to work at their own time and location.

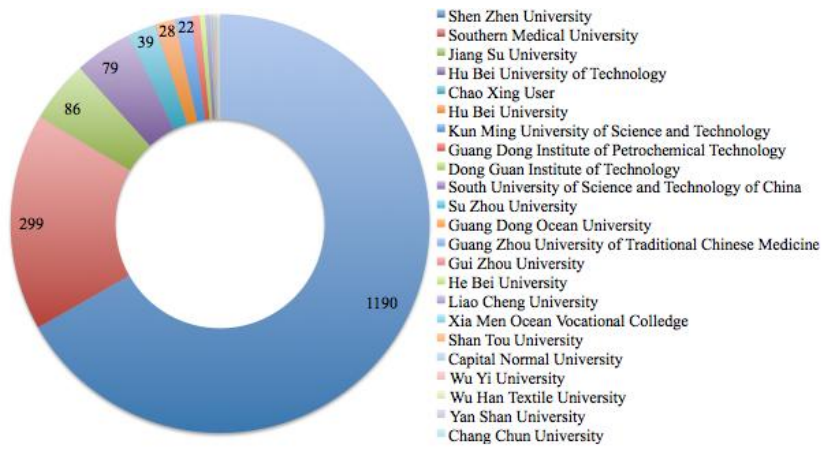

Fig. 1. Pie chart of registrants in FOC. In the pie chart, the arc length of each slice is used to represent the number of students from different origins. To each slice, we label the number of students if it is greater than 20 .

\section{B. Challenges of Learning in MOOCs}

As we described before, although students have the convenience of working through a MOOC at their own time and pace, in many courses, up to $90 \%$ drop out. Students drop out due to a variety of reasons such as a lack of incentive, insufficient prior knowledge such as math skills, a lack of focus on the Discussion forum, failure to understand the content and have no one to turn to for help, ambiguous assignments and course expectations, and lack of time due to having other priorities and commitments to fulfill which resulted in procrastination and eventually dropping out [9]. Thus, in this section, we try to study the challenges of learning in MOOCs from the eastern perspective.

To the course of Foundation of Computer Science, students needed to accrue 60 points in order to receive a certificate of completion. Grades were based on homework assignments and the final exam. To every chapter, students are required to complete the integrated exercises in the lecturer videos and the chapter-based quizzes. We demonstrated the number of students in different assignment completion period in Fig. 2. Here, A1 to A8 are used to represent the assignments from
Chapter 1 to Chapter 8, respectively. As might also be predicted, from Fig. 2, the number of students decreases between assignments. And we can find there exists a big jump between the registration and the first assignment. After the first assignment, the participants become to exhibit stability. These results are similar with other MOOCs. As we known, there exists a steep participation drop starting in the first week in most of MOOCs. In the course Bioelectricity, Fall 2012 at Duke University, 12,725 students enrolled, but only 7,761 ever watched a video, 3,658 attempted a quiz [21].

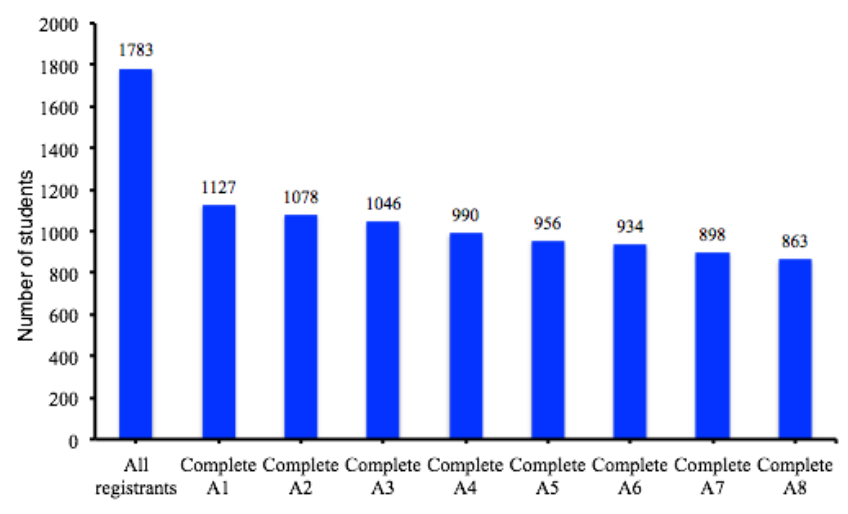

Fig. 2. Number of students in different assignment completion periods. A1 to A8 are used to represent the assignments from Chapter 1 to Chapter 8.
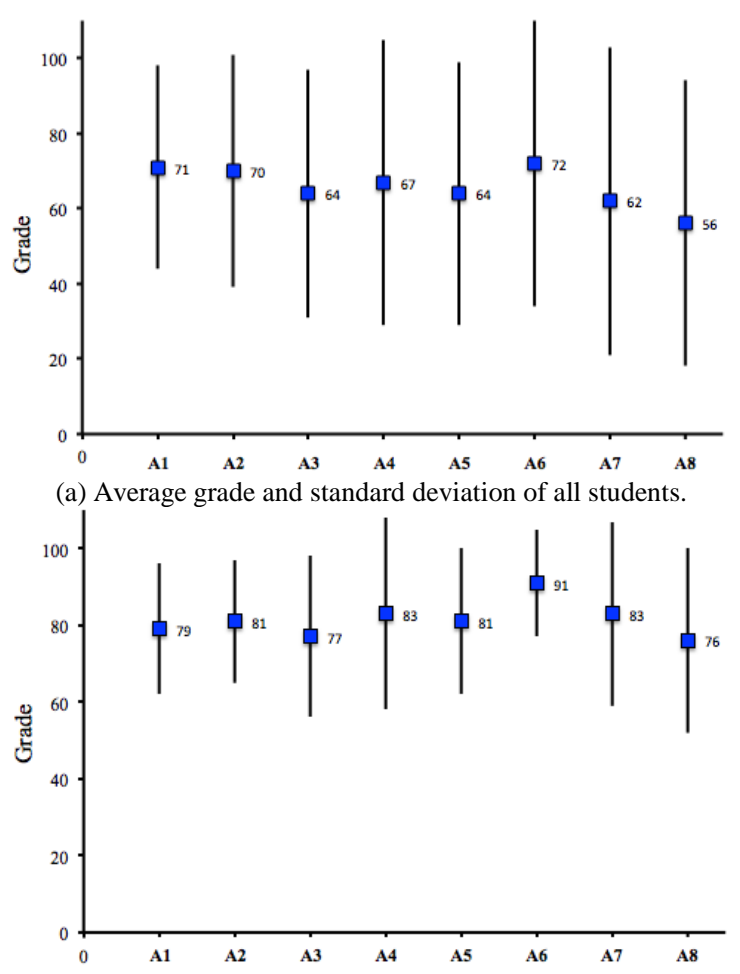

(b) Average grade and standard deviation of the students who completed all assignments.

Fig. 3. Average grade and standard deviation in each assignment. A1 to A8 are used to represent the assignments from Chapter 1 to Chapter 8. (a) is for all students, (b) is for the students who completed all assignment.

In Fig. 3, we show the average grade and the standard deviation for each assignment. Fig. 3(a) is for all registrants, and Fig. 3(b) is only for the students who completed all assignments. Here, A1 to A8 are used to represent the assignments from Chapter 1 to Chapter 8, respectively. It is obvious that the constant struggle is very important to MOOCs. The average grade of the students who keep studying is higher than the other. From Fig. 3(b), we can also 
find the average grade remains stable in all assignment.

In Fig. 4, we demonstrated the average grade and standard deviation in final exam and chapter assignments. Left part of this figure includes the students whose average assignment grade is greater than 60 points. Right part of this figure includes the students whose final exam grade is greater than 60 points. From this figure, we can find although some students dropped out their courses, the person who keeps trying finally achieves good grades.

Furthermore, in the students whose average assignment grade is greater than 60 points, $91 \%$ of them passed the final exam. And in the students who passed the final exam, only $5 \%$ of them did not pass the Chapter assignments.

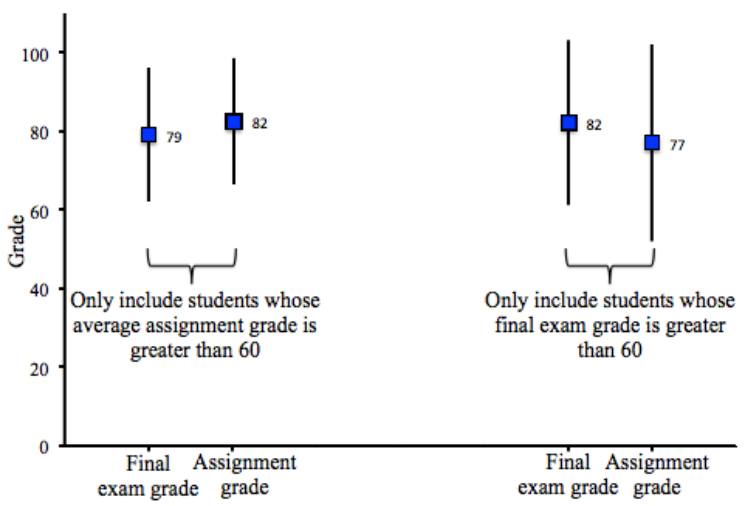

Fig. 4. Average grade and standard deviation in final exam and chapter assignments. Left part of this figure shows the grades for students whose average assignment grade is greater than 60 points. Right part of this figure shows the grades for students whose final exam grade is greater than 60 points.

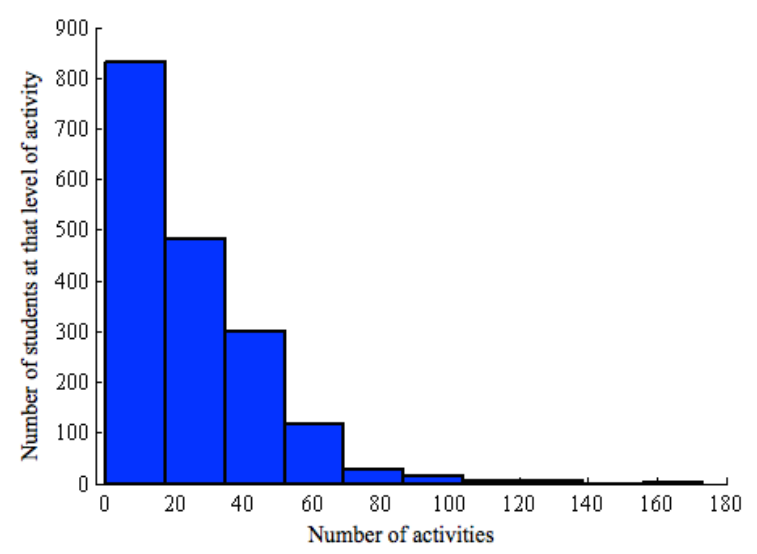

Fig. 5. Histogram of activities for students in FOC.

About $74 \%$ students from Shen Zhen University completed the course and obtained their certificates, and about $13 \%$ from other universities completed the course. The difference between the completion rates is resulted from two factors. First, the lecturers hold serials of off-line lectures in campus to answer questions from students and help them to understand the content. From the feedbacks of students, this kind of supplementary course is especially helpful for them to learn the Algorithm part, which is one of the most important parts of FOC. Previous feedback from the MOOCs revealed that participants would rather watch a hand writing an equation or codes on paper than stare at the same paper with writing already on it. Therefore, face-to-face lectures could convey a sense of immediacy, which is useful to learn Algorithm. Second, in eastern culture, many students are more accustomed to discussing the problems of course in person. Thus, if more students from the same campus even the same university residence hall, they have more possibility to share or discuss the course content. The response of the questionnaire survey also evidences our assumption. $44 \%$ admitted they tried to solve their problems by discussing with their classmates, while only $22 \%$ selected to ask questions on discussion forum. Furthermore, from the questionnaire survey, more than $60 \%$ of students did not take part in the discussions on forum, compared with only $6 \%$ of participants usually ask or answer questions. Fig. 5 below illustrates the small number of activities the vast majority of students actually made. We know that, on average, only $3 \%$ of all students participated in the discussion forum in previous MOOCs' research. Thus, we also calculated the number of posts of all students. We find about $9.5 \%$ of all students in our course asked a question, or answered a question, or made a comment.

To demonstrate the students' course progress, the survey data is shown in Fig. 6. From Fig. 6, we can find most of students do not follow the progress of the course. About $12 \%$ began to watch video lectures when the final exam is approaching. Similarity, these results have been evidenced in Fig. 7. The final exam of FOC is set as Jan. $10^{\text {th }} 2015$, which attracts more visits in this period.

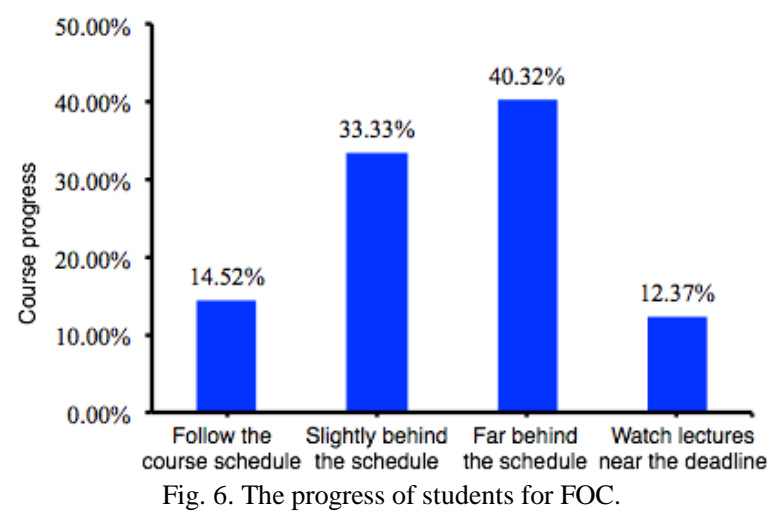

\section{Different Learning Styles in MOOCs}

As we known, the learning style has a direct and important effect on learning. In this part, we try to investigate the influence of different learning styles in MOOCs.

In our questionnaire survey, Question 11 is about the interactive experience on discussion forum, Question 12 is about the learning style, Question 16 is about the disadvantages of MOOCs, Question 18 is about the future attitude toward MOOCs. All of the choices of these questions are listed in Table I.

To analyze the co-relationship between the learning style and the interactive experience, we provided the matching matrix of Question 12 and Question 11 in Fig. 8(a). The red number is the number of students who selected the corresponding choice. Larger the number is, whiter the color is shown. From this matching matrix, we could find only less than one-third of students thought themselves as active learners (select A in Question 12). In these active learners, more than half of them took part in the discussions on the forum (select A, B, or C in Question 11). About 25\% students thought themselves as passive learners (select B in Question 12). In these passive learners, none of them has the experience of posting their questions and answering questions from 
others (select A in Question 11), while 76\% of them haven't participated in the discussion forum (select D in Question 11). Nearly half of the participants believed they would become active learners in a competitive environment (select $\mathrm{C}$ in Question 12). In these people, about $65 \%$ of them haven't participated in the discussion forum (selection D in Question
11). Although this ratio is smaller than the ratio of passive learner, it is still very high. We could make a rational inference that most of them did not think MOOC was a competitive environment, which can trigger them become active.

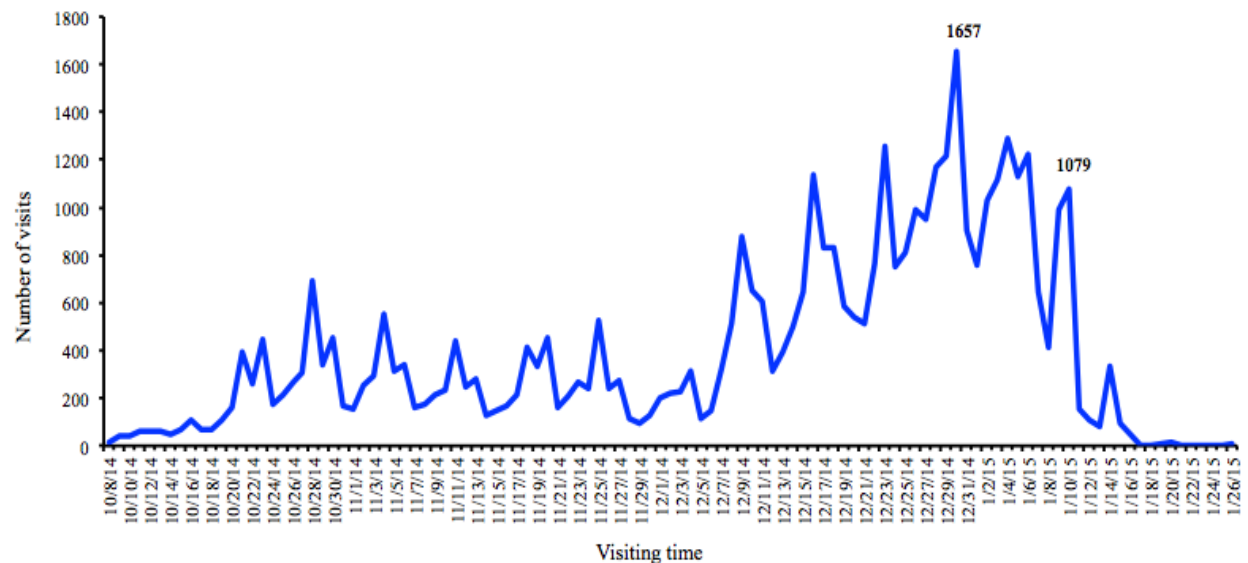

Fig. 7. The number of visits in the course "Foundation of Computer Science" period. The maximum peak value is 1657 on Dec. 29th, 2014. From Dec. 20th to Jan. 10th, the number of visits is more than other period.

\begin{tabular}{|c|c|c|c|c|c|}
\hline Question No. & Question & Choice: A & Choice: B & Choice: C & Choice: D \\
\hline $\begin{array}{l}11 \\
\text { (Single answer) }\end{array}$ & $\begin{array}{l}\text { What is your interactive } \\
\text { experience on } \\
\text { discussion forum? }\end{array}$ & $\begin{array}{l}\text { Ask question } \\
\& \text { answer questions }\end{array}$ & Post questions & Answer questions & $\begin{array}{l}\text { Do not take part in } \\
\text { the discussions on } \\
\text { forum }\end{array}$ \\
\hline $\begin{array}{l}12 \\
\text { (Single answer) }\end{array}$ & $\begin{array}{l}\text { What is your learning } \\
\text { style? }\end{array}$ & Active learning & Passive learning & $\begin{array}{l}\text { Become active learner } \\
\text { in a competitive } \\
\text { environment }\end{array}$ & 1 \\
\hline $\begin{array}{l}16 \\
\text { (Multiple } \\
\text { answers) }\end{array}$ & $\begin{array}{l}\text { What is the } \\
\text { disadvantage of } \\
\text { learning in MOOCs? }\end{array}$ & $\begin{array}{l}\text { Lack of teachers' } \\
\text { supervision and } \\
\text { management }\end{array}$ & $\begin{array}{l}\text { Learn by myself } \\
\text { makes me lack of } \\
\text { enthusiasm and } \\
\text { ambition }\end{array}$ & $\begin{array}{l}\text { Hard to pay attention, } \\
\text { which increases the } \\
\text { difficulty of learning }\end{array}$ & $\begin{array}{l}\text { Lack of practices and } \\
\text { other homework }\end{array}$ \\
\hline $\begin{array}{l}18 \\
\text { (Multiple } \\
\text { answers) }\end{array}$ & $\begin{array}{l}\text { After one semester of } \\
\text { experience, what is your } \\
\text { future attitude toward } \\
\text { learning in MOOCs? }\end{array}$ & $\begin{array}{l}\text { Understand what is } \\
\text { MOOC, I wouldn't } \\
\text { exclude the possibility } \\
\text { of learning in MOOCs }\end{array}$ & $\begin{array}{l}\text { Get used to MOOC, } \\
\text { prefer to learning } \\
\text { MOOCs than } \\
\text { traditional classroom } \\
\text { teaching }\end{array}$ & $\begin{array}{l}\text { Select MOOCs or } \\
\text { traditional education } \\
\text { based on the nature of } \\
\text { the course }\end{array}$ & $\begin{array}{l}\text { Compared with } \\
\text { MOOCs, traditional } \\
\text { classroom teaching is } \\
\text { better }\end{array}$ \\
\hline
\end{tabular}

To find out the negative arguments of MOOCs from different learning types of students in FOC, we provided the matching matrix of Question 12 and Question 16 in Fig. 8(b). The red number is the number of students who selected the corresponding choice. Larger the number is, whiter the color is shown. To the active learners (select A in Question 12), we would surprisly find almost $60 \%$ students complained of the lack of practices and homework. Less of them thought the disadvantages are the lack of teachers' supervision and management (select A in Question 16), or lack of ambition due to learn by themselves (select B in Question 16), or hard to pay attention (select $C$ in Question 16). It means to these types of students, they do not need the management or pressure from outside. They already have the ability to learn by themselves. In this case, they need different challenges, maybe more practices or homework, to help them understand the content of the course deeply. This phenomenon has never happened to other groups of learners. To the passive learners (select B in Question 12), more complaints aimed to hard to pay attention (select $\mathrm{C}$ in Question 16), and the lack of teachers' supervision (select A in Question 16). To the potential active learner or passive learner (select $\mathrm{C}$ in Question 12), 46\% participants argued that they could not focus attention on the videos (select C in Question 16), 18\% of them thought learning in MOOCs was lack of supervision and management (select A in Question 16).

To find out the future attitude toward learning in MOOCs from different learning types of students, we provided the matching matrix of Question 12 and Question 18 in Fig. 8(c). The red number is the number of students who selected the corresponding choice. Larger the number is, whiter the color is shown. We can find although different learning styles of students demonstrated different learning effects, most of learners accepted learning in MOOCs is a reasonable choice, only $9 \%$ of posts mentioned traditional classroom teaching is a better choice than MOOC. To the active learners (select A in Question 12), 24\% students mentioned they got used to MOOCs, they would prefer to learning in MOOCs than 
traditional classroom teaching (select B in Question 18). To the potential active or passive learners (select $\mathrm{C}$ in Question 12), $20 \%$ students chose the same selection (select B in Question 18). To the passive learners (select B in Question 12 ), only $16 \%$ had the same positive argument to MOOCs (select B in Question 18). These results told us the active learners are eager for new education experiences and they are willing to experiment. More importantly, according to one semesters' study, more and more participants have a deep understanding of MOOCs. We could expect, to any learning-style learners, they will compare the advantages and disadvantages of MOOCs, then select MOOCs or traditional education based on the nature of the course (select $\mathrm{C}$ in Question 18).

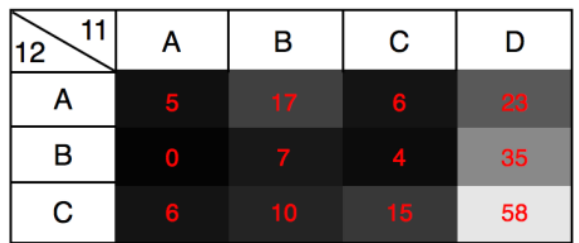

(a) Question 12 and Question 11.

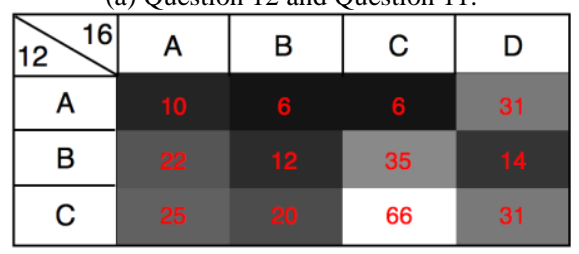

(b) Question 12 and Question 16.

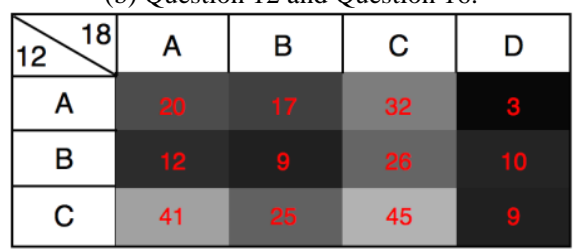

(c) Question 12 and Question 18.

Fig. 6. Matching matrix of Question 12 and other related questions. (a) is the matching matrix of Question 12 and Question 11. (b) is the matching matrix of Question 12 and Question 16. (c) is the matching matrix of Question 12 and Question 18. The red number is the number of students who selected the corresponding choice. Larger the number is, whiter the color is shown.

\section{DISCUSSION}

As the discussion in [4], how to provide instructor and student interactions is trickier in MOOCs. The analysis results of our paper also indicated that it is very important to construct a learning community to increase the interactions between students. Moreover, the role of lecturer in a MOOC differs from his role in traditional open courses, their role included: answering questions which peers could not answer in discussion forums, solving problems which students did not understand in the video lectures, encouraging the students to recommend on literature and reading resources, and sending e-mails and announcements related to the course [9]. From our study, we find the importance of off-line lectures provided by lecturers. To the MOOCs offered by the universities from eastern countries in partnership with online learning platforms, maybe it is better to provide some off-line lectures in study groups or social sessions. Furthermore, we find there exists obvious differences between learners of different learning styles. Thus, it is important to understand these differences, especially for the lecturers in MOOCs.

\section{CONCLUSION}

MOOCs have captured the attention of many higher education institutes around the world. In this paper, we try to study the motivations and challenges of learning in MOOCs from the eastern perspective. We found evidence to support both positive and negative arguments of MOOCs. MOOCs can increase an institution's reach because they could attract a large number of students and all students have the convenience of working at their own time and pace. On the other hand, due to the loose structure, most of students could not follow the schedule and the completion rate is lower than traditional courses. Furthermore, based on our studies, the face-to-face teaching and learning in participants' community should be a benefit supplement, especially in eastern culture. And it is necessary to set up different learning schedules and methodologies for learners of different learning styles. The next step of our research is to carry out more sophisticated predictive analyses, exploring relationships between the students' use of course components and their achievement, by statistical methods and machine learning models.

\section{ACKNOWLEDGEMENTS}

This research was supported by NSFC 61373122.

\section{REFERENCES}

[1] K. F. Hew and T. Brush, "Integrating technology into K-12 teaching: Current knowledge gaps and recommendations for future research," Educational Technology Research and Development, vol. 55, no. 3, pp. 223-252, 2007.

[2] A. M. Fairhurst and L. L. Fairhurst, Effective Teaching, Effective Learning, California: Davies-Black Publishing, 1995.

[3] K. Robinson, Out of Our Minds: Learning to Be Creative, Capstone Publishing Ltd, Oxford/GB, 2011.

[4] L. Pappano. (November 2012). The year of the MOOC. [Online]. Available:

http://www.nytimes.com/2012/11/04/education/edlife/massive-openonline-courses-are-multiplying-at-a-rapidpace.html

[5] H. Hu, "MOOC migration," Diverse: Issues in Higher Education, vol. 30, no. 4, pp. 10-11, 2013.

[6] B. Voss. (March 2013). Massive open online courses (MOOCs): A primer for university and college board members. Association of Governing Boards of Universities and Colleges [White Paper]. [Online].

Available: agb.org/sites/agb.org/files/report_2013_MOOCs.pdf

[7] A. Koutropoulos, M. S. Gallagher, S. C. Abajian, I. Waard, R. J. Hogue, N. O. Keskin, and C. O. Rodgriguez, "Emotive vocabulary in MOOCs: Context \& participant retention," European Journal of Open, Distance and e-Learning, vol. 1, pp. 1-23, 2012.

[8] D. Wiley and J. Hilton, "Openness, dynamic specialization, and the disaggregated future of higher education," International Review of Research in Open and Distance Learning, vol. 10, no. 5, pp. 1-16, 2009.

[9] K. F. Hew and W. S. Cheung, "Students' and instructors' use of massive open online courses (MOOCs): Motivations and challenges," Educational Research Review, vol. 12, pp. 45-58, 2014.

[10] A. J. Jacobs. (April 2013). Two cheers for web U! New York Times. [Online]. 162(56113), pp. 1-7. Available: http://www.nytimes.com/2013/04/21/opinion/sunday/grading-the-mo oc-university.html?smid=pl-share\&_r=1\&

[11] Y. Belanger and J. Thornton. (Feb. 2013). Bioelectricity: A quantitative approach Duke University's first MOOC. [Online]. Available:

http://dukespace.lib.duke.edu/dspace/bitstream/handle/10161/6216/D uke_Bioelectricity_MOOC_Fall2012.pdf?sequence $=1$

[12] J. Rice, "What I learned in MOOC," College Composition and Communication, vol. 64, no. 4, pp. 695-703, 2013.

[13] K. Jordan. "Initial trends in enrolment and completion of massive open online courses," The International Review of Research in Open and Distance Learning, vol. 15, no. 1, pp. 133-160, 2014. 
[14] M. Chafkin. (2013). Udacity's Sebastian thrun, godfather of free online education changes course. Fast Company. [Online]. Available: http://www.fastcompany.com/3021473/udacitysebastian-thrun-uphill -climb

[15] E. H. Dagmar, "MOOCs motivation and communication in the cyber learning environment," Procedia-Social and Behavioral Sciences, vol. 131, no. 5, pp. 29-34, 2014.

[16] M. Cusumano, "Are the costs of "free' too high in online education?" Communications of the ACM, vol. 56, no. 4, pp 26-29, 2013.

[17] P. J. Muñoz-Merino, J. Ruipérez-Valiente, C. Alario-Hoyos, M. Pérez-Sanagustín, and C. Delgado-Kloos, "Precise effectiveness strategy for analyzing the effectiveness of students with educational resources and activities in MOOCs," Computers in Human Behavior, vol. 47, pp. 108-118, 2015.

[18] A. M. F. Yousef, M. A. Chatti, U. Schroeder, and M. Wosnitza, "MOOCs - A review of the state-of-the-art," in Proc. $6^{\text {th }}$ International Conference on Computer Supported Education, vol. 3 , 2014, pp. 9-20.

[19] N. K. Denzin and Y. S. Lincoln, Strategies of Qualitative Inquiry, London: SAGE Publication, 2003.

[20] L. Breslow, D. E. Pritchard, J. Deboer, G. S. Stump, A. D. Ho, and D. T. Seaton, "Studying learning in the worldwide classroom research into eDX's first MOOC," Research \& Practice in Assessment, pp. 13-25, 2013.

[21] D. Catropa. (March 2013). Big (MOOC) data. Inside Higher Ed. [Online]. http://www.insidehighered.com/blogs/stratedgy/big-moocdat

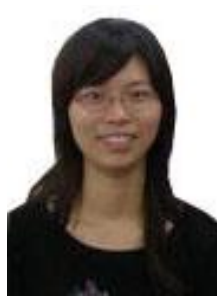

Sheng-Hua Zhong was born in 1982. She received her B.Sc. in optical information science and technology from Nanjing University of Posts and Telecommunication in 2005 and the M.S. in signal and information processing from Shenzhen University in 2007. She got her Ph.D. from the Department Computing, the Hong Kong Polytechnic University in 2013

She worked as a postdoctoral research associate in the Department of Psychological \& Brain Sciences at the Johns Hopkins University from 2013 to 2014. Currently, she is an assistant professor in College of Computer Science \& Software Engineering at Shen Zhen University in Shen Zhen. Her research interests include multimedia content analysis, cognitive science, psychological and brain science, and machine learning.

Dr. Zhong got the Qualcomm Award in ACM MM 2011, Women Research Award in ACM ICIMCS 2011, and Best Paper Award in ACM ICIMCS 2010. Dr. Zhong has served as a reviewer for many world-class journals, such as IEEE Trans. on Image Processing, IEEE Trans. on Neural Networks and Learning Systems, Expert Systems with Applications, Neurocomputing, and Multimedia Tools and Applications.

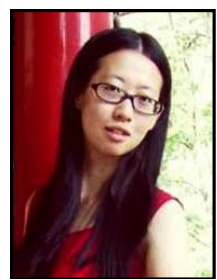

Qun-Bo Zhang was born in 1993. She is an undergraduate student in College of Computer and Software in Shen Zhen University.

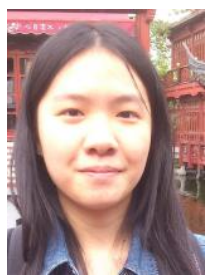

Zheng-Ping Li was born in 1993. She is an undergraduate student in College of Computer and Software in Shen Zhen University.

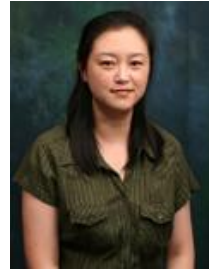

Yan Liu received her B. Eng. from the Department of Electrical Engineering at Southeast University in 1996 and the M.Sc. from School of Business at Nanjing University in 1999. She got her Ph.D. from the Department of Computer Science at Columbia University in 2005.

Currently, she is an associate professor in the Department of Computing at the Hong Kong Polytechnic University. She is the director of cognitive computing lab. Her research interests include multimedia content analysis, machine learning, cognitive science and brain modeling.

Dr. Liu got the Outstanding Organization Award in ACM ICMR 2012, Quality Reviewer Award in IEEE ICME 2011, Best Paper Award in ACM ICIMCS 2010, Special Recognition Award from Intel Research in 2003, IBM Fellowship in 2001, and Best Paper Award in IASTED ICIMSA 2000. She has served as TPC Chair in ICIMCS 2012 and Publication Chair in ACM Hong Kong Chapter. She has been TPC member for many top conferences such as AAAI and SIG MM, and reviewer for many world-class journals, such as IEEE Trans. on Multimedia and IEEE Trans. on Knowledge and Data Engineering. Dr. Liu has been Principle Investigator for ten projects of multimedia search engineer and big data analysis. 